\title{
HOUSEHOLD EXPENDITURE IN RESPONSE TO NATURAL DISASTERS
}

\author{
Eny Sulistyaningrum \\ Faculty of Economics and Business \\ Universitas Gadjah Mada \\ (eny@ugm.ac.id)
}

\begin{abstract}
Natural disasters have increased in their frequency, and the intensity of their destruction over the last ten years in Indonesia. Households usually respond to these difficulties by cutting their consumption, especially for non-essential goods. Arguably natural disasters are exogenous events, so this paper uses the exogenous variation from natural disasters as a natural experiment design to estimate the effect of disasters on household expenditure. When a certain group is exposed to the causal variable of interest, such as a disaster, and other groups are not, the Difference In Difference model (DID) can be used for estimation. Using a micro level survey data set from the Indonesian Family Life Survey (IFLS) which covers approximately 83 percent of the Indonesian population within the survey area, this paper examines the effects of natural disasters on household expenditure. This paper also examines whether there are any different impacts from different types of disasters. The finding is there are no significant effects of disasters on total household expenditure for households living in disaster regions, whether they are affected directly or not by the disaster.
\end{abstract}

Keywords: natural disasters, household expenditure, DID, natural experiment

\section{INTRODUCTION}

Natural disasters are always associated with the disruption of local economies and hurting the local populations. Disasters are negatively correlated with human capital outcomes and also have a large negative effect on the economy. The destruction of property, assets, infrastructure, and also crop losses will affect the local economy and the well-being of households who are directly affected. All these direct impacts of disasters automatically disturb the flow of goods and services, and also the production process, as a result of scarce resources. Consequently, these conditions cause the price of goods and services to increase. Households usually respond to these difficulties by cutting their consumption, especially for non-essential goods. For essential goods such as food, households try to keep the same level of consumption or only reduce their consumption slightly, although the price of food increases due to the scarcity of food supplies because of the natural disasters.

As natural disasters have increased in number, and also in the intensity of the resulting destruction in the last few years in Indonesia, it becomes very important to examine the impact of disasters on the local economies in disaster regions. There are several types of disasters that often occur in Indonesia, from the less harsh to the most destructive ones, such as floods, earthquakes, tsunamis, landslides, windstorms, drought, and volcanic eruptions. Natural disasters always leave serious problems for the populations in disaster regions, especially in a country like Indonesia, which is highly populated. A lot of literature has confirmed that disasters are negatively associated with many aspects of human life, such as human capital outcomes, consumption, local economies, and other aspects. Considering all these conditions, studies of the impact of disasters, especially for Indonesia, are needed and become very important in order to have a better response when disasters occur in the future. Hence, this paper tries to capture the response of households' expenditure to the previous disasters.

More than 4,000 disasters occurred during the period from 2000 to 2011, and were recorded by the National Disaster Management Agency (BNPB) across various regions. Some of them 
were very destructive, and killed many people in some of the affected regions in Indonesia. The most destructive one was the earthquake and tsunami in Aceh on the $26^{\text {th }}$ of December, 2004 with a 9.1 - 9.3 moment magnitude scale, and the longest duration in history, of around 10 minutes. This disaster killed approximately 230,000 people in fourteen countries, and more than half of these people, 126,915, were from Indonesia. In addition, according to the BNBP, 37,063 people were missing and 655,000 people were made homeless across Aceh province. The second destructive disaster was an earthquake on the $26^{\text {th }}$ of May, 2006 in Yogyakarta province. More than 6,000 people were killed in a 6.3 magnitude earthquake and about 130,000 were left homeless. Another serious disaster was the floods in Jakarta in February 2007. Around 30 people were killed and approximately 340,000 left homeless. Another earthquake in West Sumatra that measured 5.8-6.4 on the Richter scale killed approximately 50 people on the $6^{\text {th }}$ of March, 2007.

Table 1 shows the total number of disasters during the last decade across the various provinces of Indonesia. Rows in grey are the IFLS regions where all the IFLS data samples were taken from. We provide the percentage of the population killed and the percentage of the population evacuated in order to see the region which suffered the most from disasters. Aceh province has the highest percentage of deaths to population and also the total number of evacuated people to population. It is not surprising since the most destructive disaster during the last decade was in Aceh. As Aceh is an outlier due to the huge number of victims from the impact of the earthquake and tsunami in 2004 and is not in the IFLS sample, we excluded Aceh from the following discussion.

For an empirical analysis, this study determined the disaster regions as being DI Yogyakarta, DKI Jakarta and West Sumatra. Those three provinces were chosen because of having the highest percentages for both the dead and evacuated people in the region. Furthermore, natural disasters can be determined more specifically based on the occurrence of disasters in each disaster region. Yogyakarta, with its big earthquake, has the highest percentage for both the percentages of dead and evacuated people. West Sumatra is above average in terms of its percentage of evacuated people, after only having experienced a small earthquake, and also in terms of the percentage of dead people there, but although West Sumatra is below average, the value is just below DI Yogyakarta, which is quite high compared to other provinces. DKI Jakarta, with its floods, has an above average percentage of evacuated people although the percentage of dead people is quite low. Another strong argument is that DKI Jakarta experiences flooding almost every year, which always presents severe problems.

This paper has several objectives. First, it looks at the way households cope with the effects of natural disasters by their household expenditure. There are several types of expenditure to be observed with regards to the impact of disasters: total expenditure, educational expenditure and also food expenditure. In addition to the households' expenditure, this paper also estimated the impact of disasters on wages. The second main objective is to examine whether there is any difference in the impact different types of disasters have. This paper observed three types of disasters: large earthquakes, small earthquakes, and floods. This paper contributes to the international literature in several aspects. Compared to other literature that discusses the impact of disasters on expenditure or budgets, this study uses a variety of data on households' expenditure and also on incomes (wages). On top of that, for food expenditure, there are two separate estimates for those who obtain their food from market purchases, and those who get their food by producing it themselves on their farms/smallholdings. 
Table 1: Total number of disasters, deaths and evacuations from 2000 to 2011

\begin{tabular}{|c|c|c|c|c|c|}
\hline No & Province & $\begin{array}{l}\text { Total number of } \\
\text { disasters }\end{array}$ & Population & $\begin{array}{l}\% \text { death/ } \\
\text { pop }\end{array}$ & $\begin{array}{c}\% \text { evacuations/ } \\
\text { pop }\end{array}$ \\
\hline 1 & Aceh & 204 & $4,494,410$ & 3.713 & 23.539 \\
\hline 2 & Bali & 58 & $3,890,757$ & 0.001 & 0.039 \\
\hline 3 & Bangka-Belitung & 73 & $1,223,296$ & 0.004 & 0.036 \\
\hline 4 & Banten & 63 & $10,632,166$ & 0.001 & 0.523 \\
\hline 5 & Bengkulu & 22 & $1,715,518$ & 0.007 & 0.038 \\
\hline 6 & DI Yogyakarta & 44 & $3,457,491$ & 0.146 & 40.973 \\
\hline 7 & DKI Jakarta & 59 & $9,607,787$ & 0.001 & 6.908 \\
\hline 8 & Gorontalo & 43 & $1,040,164$ & 0.002 & 5.731 \\
\hline 9 & Jambi & 43 & $3,092,265$ & 0.001 & 2.539 \\
\hline 10 & West Java & 691 & $43,053,732$ & 0.003 & 1.822 \\
\hline 11 & Central Java & 863 & $32,382,657$ & 0.006 & 2.965 \\
\hline 12 & East Java & 388 & $37,476,757$ & 0.001 & 0.480 \\
\hline 13 & West Kalimantan & 53 & $4,395,983$ & 0.001 & 3.601 \\
\hline 14 & South Kalimantan & 108 & $3,626,616$ & 0.002 & 6.042 \\
\hline 15 & Central Kalimantan & 16 & $2,212,089$ & 0.000 & 0.278 \\
\hline 16 & East Kalimantan & 60 & $3,553,143$ & 0.002 & 2.983 \\
\hline 17 & Riau Kepulauan & 6 & $1,679,163$ & 0.000 & 0.000 \\
\hline 18 & Lampung & 87 & $7,608,405$ & 0.001 & 0.066 \\
\hline 19 & Maluku & 29 & $1,533,506$ & 0.005 & 0.591 \\
\hline 20 & North Maluku & 30 & $1,038,087$ & 0.001 & 1.526 \\
\hline 21 & West Nusa Tenggara & 83 & $4,500,212$ & 0.001 & 2.104 \\
\hline 22 & East Nusa Tenggara & 253 & $4,683,827$ & 0.008 & 1.144 \\
\hline 23 & Papua & 35 & $2,833,381$ & 0.007 & 1.241 \\
\hline 24 & West Papua & 8 & 760,422 & 0.023 & 4.548 \\
\hline 25 & Riau & 67 & $5,538,367$ & 0.001 & 2.156 \\
\hline 26 & West Sulawesi & 24 & $1,158,651$ & 0.003 & 0.548 \\
\hline 27 & South Sulawesi & 176 & $8,034,776$ & 0.005 & 0.529 \\
\hline 28 & Central Sulawesi & 77 & $2,635,009$ & 0.005 & 2.904 \\
\hline 29 & South East Sulawesi & 205 & $2,232,586$ & 0.004 & 0.685 \\
\hline 30 & North Sulawesi & 72 & $2,270,596$ & 0.006 & 5.187 \\
\hline 31 & West Sumatra & 183 & $4,846,909$ & 0.042 & 4.429 \\
\hline 32 & South Sumatra & 58 & $7,450,394$ & 0.001 & 0.094 \\
\hline \multirow[t]{3}{*}{33} & North Sumatra & 146 & $12,982,204$ & 0.010 & 1.101 \\
\hline & Total & 4,327 & $237,641,326$ & - & - \\
\hline & Average & & & 0.076 & 2.835 \\
\hline
\end{tabular}

Source: BNPB. Note: rows in grey are for the IFLS provinces.

This study uses panel data from the Indonesian Family Life Survey IFLS4 (2007) and IFLS3 (2000). In addition, there are two other data sets used: an official disaster data base from the National Disaster Management Agency (BNPB=Badan Nasional Penanggulangan Ben- cana) of Indonesia and statistical data on Indonesia from the Central Bureau of Statistics of Indonesia (BPS=Badan Pusat Statistik). Moreover, this study used a Difference In Differences (DID) analysis. This paper used this analysis for estimating the impact of disasters on 
households' expenditure. The key assumption of DID is on the potential outcome of the treatment group in the absence of natural disasters. In addition, DID also solves how to get this group when there is no data on what would have happened to individuals affected by natural disasters if the disasters did not occur. Therefore, DID tries to find the solution to estimate this group by using other individuals that they could not observe at the same time.

A considerable amount of literature has been published on the effects of disasters on welfare, especially on income or expenditure. Some studies use income as the outcome variable, other studies use household expenditure. The most influential study on the effects of disasters on family income is Ureta (2005) who examined the impact of Hurricane Mitch on family budgets and children's schooling in Nicaragua in November 1998. Using the Living Standards Measurement Survey Data 1998 and 2001 for Nicaragua, where the 1998 survey provided the pre-treatment data and the 2001 survey provided the post-treatment data, Ureta defined a control group as the area that was hit by Mitch but in which the households were not affected, particularly in rural areas, and the treatment group as the area affected by Mitch.

Ureta estimated the impact of disasters on family incomes using the DID approach. The estimation was run separately between rural and urban areas and the findings reported that the impact on family incomes was different between the rural and urban areas. In the rural areas, the family income of households affected by the hurricane decreased from $\mathrm{C} \$ 19,316$ to $\mathrm{C} \$ 18,705$ in the year after the disaster, or by approximately $3 \%$, but in 2001 the family incomes increased significantly in real terms, by almost $16 \%$. However, in the urban areas, households affected by the hurricane suffered a greater loss in their incomes than that experienced by the rural areas, from $\mathrm{C} \$ 36,563$ to $\mathrm{C} \$ 23,720$. This was about $35 \%$ lower than before the disaster occurred. Two years after the disaster, household incomes were back to the pre-disaster condition at 1998 income levels. The most interesting feature of Ureta's study was that the households in the urban areas were more badly affected by disasters than the households in the rural areas.

A recent study by Jacobsen (2012) examined the impact of Hurricane Mitch (in 1998) on households' incomes in Nicaragua, especially on rural income generation or agricultural productive assets. Using the same data set as Ureta (2005) - Nicaraguan Living Standards Measurement Studies (LSMSs) - Jacobsen estimated the impact of disasters by using a DID model. Although Jacobsen used the same data as Ureta, Jacobsen developed some important analysis that was not used by Ureta. He measured the relative impact of the hurricane among affected households. In addition, he also verified whether a geographical poverty trap existed in the disaster areas. Jacobsen found that households were not seriously affected by disasters in their ability to generate income based on their productive assets, therefore they could maintain their consumption levels after the disaster occurred. Furthermore, he also confirmed that households at the lower end of the wealth distribution chain were more sensitive and vulnerable to shocks. The poorest households were badly affected.

Another study on the effect of disasters on expenditure was conducted by Kochar (1999). He explored the impact of crop shocks on consumption in rural India. Using a panel data set from the Indian Farm Households from 1979 to 1984, Kochar (1999) applied a dynamic model by considering the agricultural season in two stages: the planting stage and the output stage. Each stage was influenced by the price of output, female and male family labour hours, and the time of the crop shock. This study used information on aggregate household consumption, the labour hours of family members, their gender, the place of work of family members (whether they worked only on the farm or somewhere other than the farm), and other observed covariates. The important finding from this study was that households could smooth their consumption during the time of a crop shock by increasing their hours of work and 
shifting from own-farm production to the labour market.

An interesting study on the impact of disasters on consumption and expenditure was conducted by Cameron and Worswick (2001). This research is interesting since they analysed whether households could adjust their consumption during hard times in response to permanent incomes and transitory incomes. For expenditure, they only focused on educational expenditure, to avoid any measurement error in total expenditure because of the poor reporting of non-food expenditure. Cameron and Worswick studied the impact of crop loss due to weather shocks and droughts on households' educational expenditure in Indonesia.

Cameron and Worswick (2001) estimated a model of educational expenditure in response to crop losses. First, they estimated permanent and transitory incomes separately. Then, they estimated the total expenditure equation as a function of permanent income, transitory income and household characteristics. Households who could smooth their consumption during the time of a crop loss, and had a marginal propensity to consume out of their permanent income, were given the value 1 , while that for a transitory income was zero. Therefore, a zero coefficient on transitory income was evidence that the households could smooth their consumption. Using the Indonesian Family Life Survey data from 1993, Cameron and Worswick (2001) examined educational expenditure. In contrast to Kochar (1999), they found that households were not able to smooth their consumption at the time of a crop loss, so they were most likely to reduce educational expenditure, especially for girls.

Baez and Santos (2008) examined the effects of two strong earthquakes in 2001 on household incomes and poverty in El Salvador. They explored the long-term consequences of disasters on human and economic welfare. Using 700 households from a longitudinal survey of rural households and a linear probability DID model, they found that earthquakes caused households' incomes to fall by one third. Furthermore, in the long term, the earthquakes had negative effects on potential earnings through the reduction in physical and human capital accumulation. Poor households were more likely to take their children out of school in the face of disasters. This conclusion is similar to Cameron and Worswick's (2001) study in Indonesia, where households were more likely to cut educational spending, especially for girls' education, during hard times. Overall, disasters are negatively associated with economic development.

Dorosh and Smith (2003) examined the impact of floods in Bangladesh in 1998 on household incomes, consumption and nutritional outcomes. They also observed the impact of price changes, due to disasters, on household food security. Using a panel data set covering 757 rural households, they observed how households in Bangladesh coped with disasters in several ways: by reducing their expenditure, selling assets and borrowing. More than $60 \%$ of poor people borrowed money immediately following the floods. They used the money they borrowed to purchase food and to finance other expenses, such as health, education and production. In addition, using an econometric analysis of households' calorie consumption with a household fixed effect, they examined the impact of price changes on household food security.

The main findings are as follows. The first finding is related to the effect of disasters on total household expenditures. This paper finds that being in disaster regions, whether a household is affected by the disaster or not has no impact on the total household expenditure. For the impact of disasters on food expenditure, there are differences between market purchased and own produced expenditure for households who are affected directly by the disasters. Disasters are positively associated with market purchased expenditure, but negatively associated with own produced expenditure. There is a big reduction in own produced expenditure as households are more likely to buy food. For educational expenditure, only households who are directly affected by disasters have a lower educational expenditure. In addition, looking at the impact of disasters on wages, there are no significant impacts of disasters on wages. More- 
over, looking separately at different disasters, only households who are affected directly by big earthquakes and floods reduced household expenditure and educational expenditure, and there are no serious impacts for those who are directly affected by small earthquakes.

\section{DATA SOURCES}

This study used panel data from the Indonesian Family Life Survey IFLS3 (2000) and IFLS4 (2007). In addition, there were two other data sets used: an official disaster data base from the National Disaster Management Agency (BNPB=Badan Nasional Penanggulangan Bencana) of Indonesia and statistical data on Indonesia from the Central Bureau of Statistics of Indonesia (BPS=Badan Pusat Statistik).

\section{Disasters}

The IFLS defines households as being affected by a disaster if the disaster was severe enough to cause death or major injuries to a member of the household, cause direct financial loss to the household, or cause the household's members to relocate. The IFLS reports on several types of natural disasters such as earthquakes, tsunamis, landslides, floods, volcanic eruptions, and windstorms. Another important definition is the disaster region. Since most of the regions in Indonesia experience disasters, it is important to determine which region is a disaster region, so it can receive assistance. A disaster region is defined as a region which has had a more serious disaster than another region. Neumayer and Plumper (2007), in order to measure the scale of the disaster, used the number of people killed during a disaster divided by the total population as a proxy of the strength of the disaster, but this study uses two proxies as measurements of the strength of a disaster (the percentage of the number of people killed to the total population, and the other proxy is the percentage of the number of people evacuated to the population). For this reason, a region which experiences disasters almost every year which affect the local economy can be captured by using these two proxies (see Table 1).
Based on the disaster information above, this study defines dummies $\mathrm{D}$ (disaster region) and A (being affected by disaster). $\mathrm{D}$ is equal to 1 if individuals are in the disaster region at the time of the disaster, and $\mathrm{A}$ is equal to 1 if individuals are in the disaster region and were affected by the disaster. As explained above, the individuals who suffered financial losses, or one or more of their household members died or suffered major injuries, are defined as being affected by the disaster. Table 1 presents the number of households affected and not affected by disasters for each of the three disaster regions. Yogyakarta with its big earthquake had a large number of households affected, with almost $50 \%$ of the households there affected by the disaster, while the percentages of households affected by disasters in Jakarta and West Sumatra were less than 15 percent.

Table 2 The number of households in disaster regions according to the IFLS survey

\begin{tabular}{lrrr}
\hline & $\begin{array}{c}\text { Not } \\
\text { affected }\end{array}$ & Affected & $\begin{array}{c}\text { Total number } \\
\text { of HH }\end{array}$ \\
West Sumatra & 875 & 136 & 1,011 \\
Jakarta & 1,450 & 176 & 1,626 \\
Yogyakarta & 628 & 612 & 1,240 \\
\hline
\end{tabular}

Source: IFLS3 and IFLS 4 data survey

\section{Household Expenditures}

This study uses three main different types of household expenditure: total household expenditure, educational expenditure, and food expenditure. All values of household expenditure are calculated monthly. Total expenditure is defined as all the expenditure by the household, including food expenditure and non-food expenditure. Food expenditure is constructed from two main components: market purchased and own-produced food expenditure. Market purchased expenditure is calculated from the households' food consumption which is purchased, while own-produced expenditure is calculated from the total value of food obtained from its own production or as a gift or other assistance.

Table 3 presents the comparison of average expenditure in 2000 and 2007. All values are in real terms with 2002 as the base year. The aver- 
Table 3: Real household expenditure per month (in thousands of rupiah)

\begin{tabular}{lcccc}
\hline \multirow{2}{*}{\multicolumn{1}{c}{ Type of expenditures }} & \multicolumn{2}{c}{ Average HH expenditure } & \multicolumn{2}{c}{ Expenditure per person } \\
\cline { 2 - 5 } & 2000 & 2007 & 2000 & 2007 \\
\hline Total expenditure & 1,243 & 1,267 & 341 & 410 \\
Educational expenditure & 134 & 165 & 36 & 54 \\
Food expenditure (market purchased only) & 559 & 566 & 149 & 178 \\
Food expenditure (own produced only) & 118 & 117 & 36 & 41 \\
\hline
\end{tabular}

Note: mean size of household in $2000=5.1$, mean size of household in $2007=4.7$

Source: IFLS3 and IFLS4 data survey

age total household expenditure in the year 2000 was about IDR1,200,000 per month, which had increased by approximately 2 percent by 2007 . For educational expenditure, in 2000, the average educational expenditure was IDR134,000 per month, this had increased by around 23 percent by 2007. Furthermore, for food expenditure, market purchased expenditure is about 5 times the cost of own produced expenditure. In 2000 , the consumption of food from market purchases was about IDR550,000 per month, and from own produced food it was around IDR110,000. By 2007, the consumption of food from market purchases had increased by approximately 2 percent, while for own produced food, the consumption had decreased by a little less than 1 percent. In comparison with other expenditure, educational expenditure had the highest growth rate.

Furthermore, in order to get the real figures for the growth in household expenditure, household expenditure per person is provided. In Table 3, since the mean household size decreased between 2000 and 2007, the fact that the average total household expenditure per person increased by approximately 20 percent, and the same percentage increase is also seen for market purchased food expenditure, is surprising. The growth in educational expenditure per person seems quite high at about 50 percent.

Figure 1 presents the average total expenditure, in real terms, in 2000 and 2007 across the provinces. As this study expected, Jakarta has the highest values of total expenditure in both years at approximately IDR2.5 million per month in 2007 and around IDR2.2 million per month in 2000. Bali and South Sulawesi have a higher growth in their total expenditure from 2000 to 2007 than any other regions. In addition to Jakarta, Yogyakarta and West Sumatra as disaster regions, have average levels of expenditure. It seems in general the averages of total expenditure are not seriously affected by disasters, especially in Jakarta and West Sumatra. Meanwhile, Yogyakarta with its large earthquake had a low growth in its total expenditure. These phenomena can be observed from the differences between average real expenditure in 2000 and 2007.

In addition, non-food expenditure is categorized into two groups: frequently purchased goods and services, and less frequently purchased items. For frequently purchased goods and services, the expenditure includes electricity, water and phone bills, personal toiletries, and other household items that are always consumed on a regular basis. For less frequently purchased goods and services, expenditure is calculated from the goods and services that are relatively infrequently consumed, such as clothing, medical costs, and furniture.

\section{Educational Expenditure}

Educational expenditure was calculated from all the formal educational costs for children living in the household, and outside of the household, and also the educational costs for children in any level of education from primary school to higher education. Moreover, this expenditure is calculated from all the spending on school fees, school supplies and transportation. School fees are a summation of tuition fees, registration fees, exam fees, school contributions, and laboratory fees. School supplies are calculated from uni- 


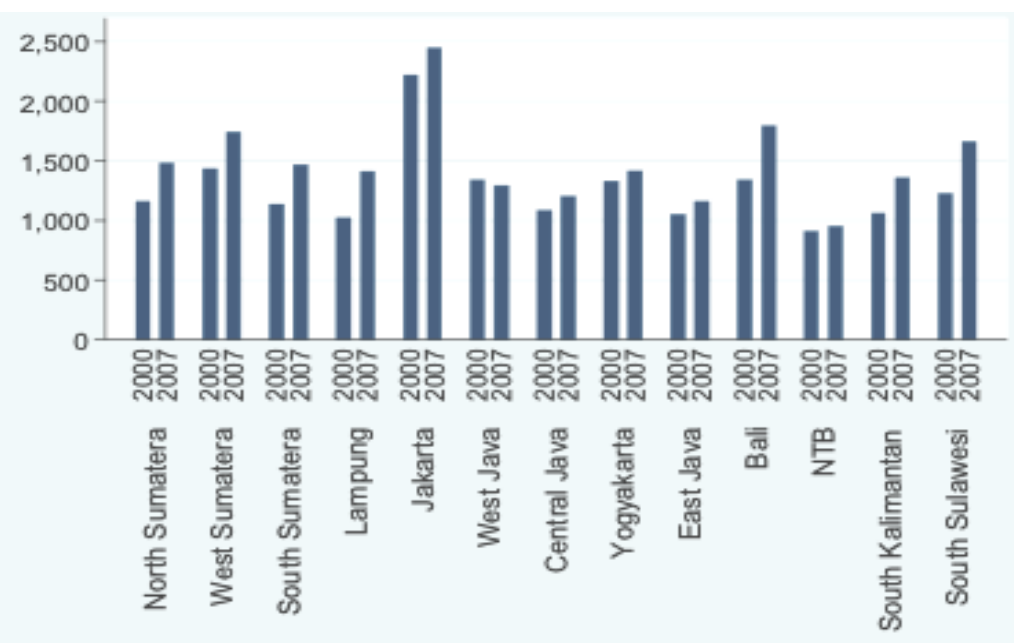

Figure 1: The average of total expenditure in 2000 and 2007 by provinces

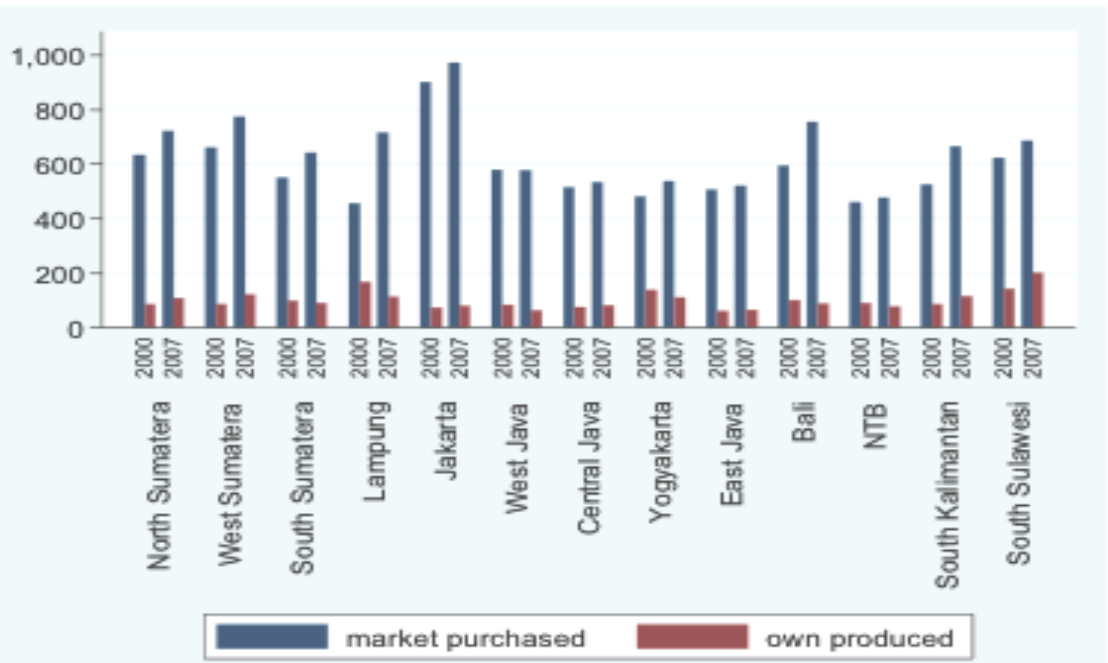

Figure 2: Food expenditures: market purchased and own produced expenditure in 2000 and 2007 across provinces

forms, books, and other schooling needs. For the transportation costs, pocket money is included in this cost. Furthermore, for children who live outside of the household, there are the same costs. The only difference is their boarding house spending. All the costs are calculated based on the previous year and the values are divided by 12 in order to generate monthly figures.

Table 4 presents the variety of average real expenditure on education. In general, the biggest portion of educational expenditure is for transportation and pocket money, followed by school fees, while the smallest portion is for school supplies. There is a similar pattern of expenditure for children living in the household and outside of the household. In addition, school fees for children living in the household have the highest growth with an almost 60 percent increase from 2000 to 2007. For those households with children living outside of the household, which is less than 15 percent of the total number of households, the allocation for educational expenditure is much bigger than that of the households with children living only in the household. This may be true because these households are usually paying schooling fees for higher education, which is more expensive than the primary and secondary education fees. In addition, for those who live far away from the school, they also have to pay for rental accommodation, since higher education institutions are mostly located in the big cities. 
Table 4: Real educational expenditure using 2002 as the base year (in rupiah)

\begin{tabular}{lrrrrl}
\hline & \multicolumn{2}{c}{2000} & \multicolumn{2}{c}{2007} & \% growth \\
\cline { 2 - 5 } & number HH & \multicolumn{1}{c}{ costs } & number HH & costs & \\
\hline Expenditure for children in HH & 5,587 & $41,785.63$ & 3,866 & $66,223.14$ & 58.48 \\
$\quad$ school fees & 5,547 & $18,709.34$ & 5,565 & $20,495.55$ & 9.55 \\
$\quad$ school supplies & 5,392 & $55,705.22$ & 5,556 & $77,934.67$ & 39.91 \\
$\quad$ transportation \& pocket money & 5,869 & $108,638.50$ & 5,841 & $137,490.40$ & 26.56 \\
\hline total (a) & & & & & \\
\hline Expenditure for children outside HH & 626 & $120,600.00$ & 511 & $145,939.30$ & 21.01 \\
$\quad$ school fees & 477 & $37,620.63$ & 501 & $47,456.55$ & 26.15 \\
$\quad$ school supplies & 493 & $119,547.50$ & 563 & $135,854.10$ & 13.64 \\
$\quad$ transportation \& pocket money & 343 & $116,816.10$ & 330 & $134,297.40$ & 14.96 \\
$\quad$ boarding house & 793 & $242,680.40$ & 802 & $273,260.20$ & 12.60 \\
\hline total (b) & 6,183 & $134,246.30$ & 6,200 & $164,876.80$ & 22.82 \\
\hline Total average (a)+(b) & & & & & \\
\hline
\end{tabular}

Note: $\mathrm{HH}=$ household

Source: IFLS3 and IFLS4 data survey

Figure 3 presents the average of real educational expenditure in 2000 and 2007 across the provinces. Almost all the provinces show that their average educational expenditure in 2007 is greater than 2000 , only Jakarta has a similar average for educational expenditure. In addition, Jakarta also has a higher educational expenditure than the other provinces in both years. This indicates that, as the biggest city in Indonesia, all costs in Jakarta are higher than in other regions, including education costs.

\section{METHODOLOGY}

\section{Empirical Strategy}

Arguably natural disasters are exogenous events, so this paper uses the exogenous variation from natural disasters as a natural experiment design to estimate the effect of disasters on household expenditure. When a certain group is exposed to the causal variable of interest, such as a disaster, and other groups are not, the DID model can be used in the estimation. There are two treatment groups: the first group is house-

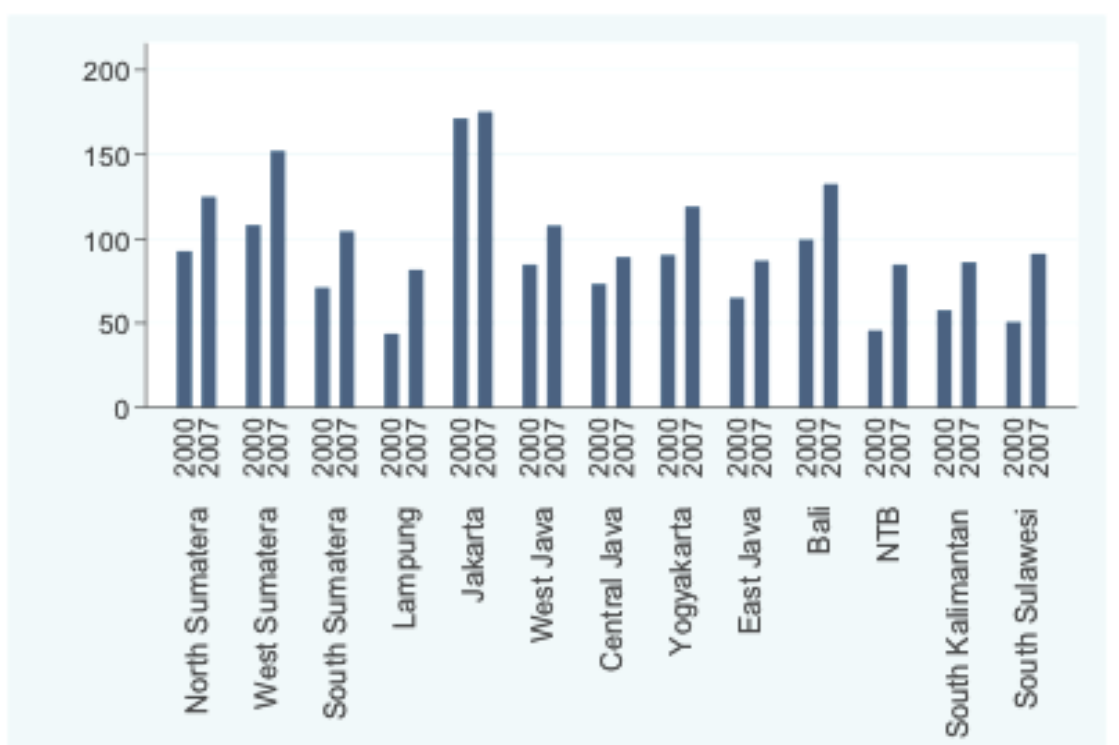

Figure 3: The average of real educational expenditure in 2000 and 2007 by provinces 
holds in the disaster region which are still there after a disaster, and the second group is households in the disaster region who have been affected by the disaster. Furthermore, the control group is comprised of households in a nondisaster region which are not being affected by any disaster. Following Angrist and Krueger (2000), the conditional mean function for household outcomes in the DID model is: $E\left[Y_{1 h} \mid h, t, r\right]$ if the household is affected by
disasters, and

$E\left[Y_{0 h} \mid h, t, r\right]$ if the household is not affected by disasters

The effect of disasters is found simply by adding two constants to:

$E\left[Y_{0 h} \mid h, t, r\right]$, so that it can be written as:

$$
\begin{aligned}
& E\left[Y_{1 h} \mid h, t, r\right]=E\left[Y_{0 h} \mid h, t, r\right]+\alpha_{1}+\alpha_{2}, \text { or } \\
& E\left[Y_{1 h} \mid h, t, r\right]-E\left[Y_{0 h} \mid h, t, r\right]=\alpha_{1}+\alpha_{2}
\end{aligned}
$$

or in another way, by using regression:

$$
\begin{aligned}
& Y_{h r t}=\alpha_{1} D_{h r t}+\alpha_{2}\left(D_{h r t} \times a_{h r t}\right)+u_{h r t} \\
& Y_{h r t}=\alpha_{1} D_{h r t}+\alpha_{2} A_{h r t}+u_{h r t}
\end{aligned}
$$

Note: $A_{h r t}=D_{h r t} \times a_{h r t}$ and $u_{h r t}=\gamma_{r}+v_{t}+\varepsilon_{h r t}$

Where $Y_{h r t}$ is the potential outcome of household $h$ in time $t$ and region $r \cdot \gamma_{r}$ is the regional effect, $v_{t}$ is the time effect, $\varepsilon_{\text {hrt }}$ is the random error. $D_{h r t}=1$ is for people in the disaster region in the time after the disaster, $a_{h r t}$ is a dummy variable that is equal to 1 if the household is directly affected by the disaster and 0 otherwise. $A_{h r t}=1$ if for people in the disaster region in the time after the disaster who have reported that they have been affected by the disaster. Furthermore, $\alpha_{1}$ and $\alpha_{2}$ are the parameters of interest. Overall, $\alpha_{1}+\alpha_{2}$ are the effects of disasters. When $D_{h r t}=0$ and $A_{h r t}=0$ then $Y_{h r t}=0$, and when $D_{h r t}=1$ and $A_{h r t}=1$ then $Y_{h r t}=\alpha_{1}+\alpha_{2}$. $\mathrm{A}_{\text {hrt }}$ is an intensity effect of disasters which is a subset of $D_{h r t}$, so $A_{h r t}$ would be a marginal effect of being affected by disasters. The DID model can be expanded by including the household covariates $X_{h r t}$ and can be written as:

$$
Y_{h r t}=\alpha_{1} D_{h r t}+\alpha_{2} A_{h r t}+\psi X_{h r t}+u_{h r t}
$$

Thus, equation (3) estimates the effect of disasters $\left(\alpha_{1}+\alpha_{2}\right)$ on the potential outcome of household $h$ in time $t$ and region $r\left(Y_{\text {hart }}\right)$ as measured by using the household's expenditure and by controlling the household covariates $X_{h r t}$ such as area, household size, parental educational backgrounds, number of household members per age category, and also regional and yearly fixed effects respectively. Control variables are needed to reduce the endogeneity problem.

\section{Household expenditure equation}

All the equations of the DID models that are used in this paper have the same variables on the right hand side, and this study estimated separately all the equations by using an OLS. The complete DID model in this study can be written as:

$$
\begin{aligned}
\text { Lhhexp }_{h r t}= & \alpha_{01}+\alpha_{11} D_{h r t}+\alpha_{21} A_{h r t}+\psi_{1} X_{h r t} \\
& +\gamma_{1 r}+v_{1 t}+\varepsilon_{1 h r t} \\
\text { Lbuyexp }_{h r t}= & \alpha_{02}+\alpha_{12} D_{h r t}+\alpha_{22} A_{h r t}+\psi_{2} X_{h r t} \\
& +\gamma_{2 r}+v_{2 t}+\varepsilon_{2 h r t} \\
\text { Lownexp }_{h r t}= & \alpha_{03}+\alpha_{13} D_{h r t}+\alpha_{23} A_{h r t}+\psi_{3} X_{h r t} \\
& +\gamma_{3 r}+v_{3 t}+\varepsilon_{3 h r t} \\
\text { Leducexp }_{h r t}= & \alpha_{04}+\alpha_{14} D_{h r t}+\alpha_{24} A_{h r t}+\psi_{4} X_{h r t} \\
& +\gamma_{4 r}+v_{4 t}+\varepsilon_{4 h r t} \\
\text { Lwages }_{h r t}= & \alpha_{05}+\alpha_{15} D_{h r t}+\alpha_{25} A_{h r t}+\psi_{5} X_{h r t} \\
& +\gamma_{5 r}+v_{5 t}+\varepsilon_{5 h r t}
\end{aligned}
$$

The dependent variables in the equations above are Lhhexp ${ }_{h r t}$, Leducexp ${ }_{\text {hrt, Lbuyexp }}$ hrt, Lownexp $_{\text {hrt }}$, and Lwages hrt $_{\text {. Log is used for each }}$ variable in order to get an elasticity of price. Lhhexp $_{\text {hrt }}$ is the log of total household expenditure. Leducexphrt is the $\log$ of educational expenditure. Lbuyexp $_{\text {hrt }}$ is the log of food expenditure from market purchases. Lownexp hrt is the $\log$ of food expenditure by estimating the value of own produced food. Lwages hrt $_{\text {in }}$ is the $\log$ of the head of the household's wages. All household expenditure and wages are measured using monthly household expenditure. The main explanatory variables are $D_{h r t}$ and $A_{h r t}$ that capture the natural disaster variables. $D_{h r t}$ is a dummy variable, equal to 1 if household $h$ was in the disaster region with expenditure after the disaster. $A_{h r t}$ is a dummy variable, equal to 1 if 
household $h$ was in the disaster region and was affected by the disaster. In addition, vector $X_{h r}$ contains the other explanatory variables to capture the household's characteristics such as the area where they live, the household's size, and the number of kids or adults in certain age groups. The variables $\gamma_{r}$ and $v_{t}$ are used to control for regional and yearly fixed effects respectively. The inclusion of the regional dummy variables reduces the potential bias from unmeasured regional shocks. Year dummy variables are useful to control for year specific characteristics and control for other changes in the year before and after the disaster. Moreover, in order to see whether different types of disasters have different impacts on household expenditure, this paper replaces the main explanatory variables which were dummies $D_{h r t}$ and $A_{h r t}$ by using dummy variables of $D_{h r t}$ and $A_{h r t}$ which belong to specific types of disasters. There are 3 dummies for $D_{h r t}$ (for a big earthquake, a small earthquake and a flood), and the same for the 3 dummies for $A_{h r t}$. In order to check the sensitivity of dummy variables of interest $\left(D_{h r t}\right.$ and $\left.A_{h r t}\right)$, this study also estimated the DID model equation by dropping all the control variables except $D_{h r t}$ and $A_{h r t}$.

\section{EMPIRICAL RESULTS}

This section discusses the results of the impact of natural disasters on household expenditure. There are two main estimation results: (1) the average impact of natural disasters on household expenditure and food expenditure, (2) the impact of natural disasters on educational expenditure and wages.

\section{The Impact of Disasters on Total and Food Expenditure}

With the DID model, this study estimated separately the impact of disasters based on the type of expenditure using OLS. Total household expenditure and food expenditure (market purchased and own produced expenditure) were presented together, since food expenditure is a bigger share of the total expenditure. Educational expenditure and wages were presented separately. Table 5 presents the estimation results for total and food expenditure. There is no negative effect of being in a disaster region after a disaster. This is true since only certain parts of a disaster region may be badly affected by a disaster, for instance the earthquake in Yogyakarta. The region there with the most destruction was Bantul, other areas such as Sleman and Yogyakarta city itself were not so badly affected. This is indicated by all of the coefficients of D. Households increased their expenditure on own produced food by approximately 20 percent on average, at a 10 percent significance level. This phenomenon could be true because these households were not directly affected, so they preferred to consume more of their own produce, since the price of food in the markets probably had increased due to the disaster.

Moreover, looking at other explanatory variables, total household expenditure and market purchased expenditure in urban areas are higher than in rural ones, but own produced expenditure in urban areas is lower than in rural areas. It is true since generally farms are located in rural areas. For household sizes, all the values are positively correlated with expenditure and are highly significant. This shows that the larger the number of household members there are, the greater the household's expenditure will be. In general, the father's educational background has no effect on expenditure, but the maternal educational background seems to have a positive and significant effect on the total and market purchased expenditure, but is negatively correlated with own produced expenditure. It could be true, because household expenditure is usually managed by the wife/mother, and the higher the maternal education is, the greater the expenditure will be, because generally the higher the maternal education is, the wealthier the family is, and a larger variety of goods are desired, especially secondary or luxury goods. In addition, more highly educated mothers are less likely to be farm workers so they probably have lower own produced food expenditure. 
Table 5: Results of the Impact of Natural Disaster on Total Household Expenditure and Food expenditure

\begin{tabular}{|c|c|c|c|c|c|c|}
\hline & \multicolumn{2}{|c|}{ Total HH exp } & \multicolumn{2}{|c|}{ Food exp: buy only } & \multicolumn{2}{|c|}{ Food exp: own prod } \\
\hline & 1 & 2 & 3 & 4 & 5 & 6 \\
\hline \multirow[t]{2}{*}{$\mathrm{D}$} & -0.000792 & 0.0283 & -0.00799 & 0.0236 & $0.172 *$ & $0.182^{*}$ \\
\hline & $(0.0663)$ & $(0.0532)$ & $(0.0663)$ & $(0.0488)$ & $(0.0817)$ & $(0.0851)$ \\
\hline \multirow[t]{2}{*}{$\mathrm{A}$} & -0.00743 & -0.101 & 0.0951 & -0.00134 & $-0.192 * * *$ & $-0.197 * * *$ \\
\hline & $(0.0507)$ & $(0.0592)$ & $(0.0615)$ & $(0.0731)$ & $(0.0597)$ & $(0.0628)$ \\
\hline \multirow[t]{2}{*}{ Urban } & & $0.324 * * *$ & & $0.282 * * *$ & & $-0.203 * * *$ \\
\hline & & $(0.0229)$ & & $(0.0270)$ & & $(0.0424)$ \\
\hline \multirow{2}{*}{ Household size } & & $0.136 * * *$ & & $0.156 * * *$ & & $0.0456^{* * *}$ \\
\hline & & $(0.00745)$ & & $(0.00848)$ & & $(0.0135)$ \\
\hline \multirow[t]{2}{*}{ Father secondary school } & & -0.0742 & & -0.128 & & -0.194 \\
\hline & & $(0.140)$ & & $(0.103)$ & & $(0.285)$ \\
\hline \multirow[t]{2}{*}{ Father higher education } & & 0.399 & & -0.0231 & & 0.289 \\
\hline & & $(0.340)$ & & $(0.0798)$ & & $(1.128)$ \\
\hline \multirow[t]{2}{*}{ Mother secondary school } & & $0.235^{* * *}$ & & 0.178 & & -0.168 \\
\hline & & $(0.0766)$ & & $(0.109)$ & & $(0.255)$ \\
\hline \multirow[t]{2}{*}{ Mother higher education } & & 0.521 & & $0.675^{* *}$ & & $-0.252 * * *$ \\
\hline & & $(0.336)$ & & $(0.291)$ & & $(0.0285)$ \\
\hline Number of HH members aged: & & $-0.0993 * * *$ & & $-0.0583 * * *$ & & $-0.0692 * * *$ \\
\hline under 6 years old & & $(0.0109)$ & & $(0.0124)$ & & $(0.0165)$ \\
\hline \multirow[t]{2}{*}{6 to 12} & & $-0.0578 * * *$ & & $-0.0558 * * *$ & & $-0.0522 * *$ \\
\hline & & $(0.00716)$ & & $(0.00777)$ & & $(0.0222)$ \\
\hline \multirow[t]{2}{*}{13 to 18} & & -0.00621 & & $-0.0493 * * *$ & & 0.0192 \\
\hline & & $(0.00761)$ & & $(0.0111)$ & & $(0.0121)$ \\
\hline \multirow[t]{2}{*}{19 to 23} & & $0.0246^{* *}$ & & 0.00565 & & 0.0252 \\
\hline & & $(0.00870)$ & & $(0.00788)$ & & $(0.0158)$ \\
\hline \multirow[t]{2}{*}{24 to 60} & & $0.0591 * * *$ & & $0.0683^{* * *}$ & & $0.0206^{*}$ \\
\hline & & $(0.00565)$ & & $(0.00643)$ & & $(0.00980)$ \\
\hline \multirow[t]{2}{*}{ Over 60} & & $-0.101 * * *$ & & $-0.123 * * *$ & & 0.0200 \\
\hline & & $(0.0105)$ & & $(0.00635)$ & & $(0.0192)$ \\
\hline Region dummies & Yes & Yes & Yes & Yes & Yes & Yes \\
\hline Time dummies & Yes & Yes & Yes & Yes & Yes & Yes \\
\hline Observation & 20,791 & 20,791 & 20,682 & 20,682 & 15,797 & 15,797 \\
\hline
\end{tabular}

Besides that, the total household members in each household, up to 18 years old and over 60 years old are negatively correlated with all expenditure, especially total and market purchased expenditure. While the total number of adults in households between 19 and 60 years old have a positive correlation with expenditure. This indicates that the age group of household members under 18 and over 60 do not require a lot of expenditure, especially for those aged under 18, as they are still of school age and do not need a lot of different expenditure types. While for the household members aged between 19 and 60, they need more expenditure, since all those household members are supposed to have jobs and usually their needs are more varied. 
Table 6 presents the impact of specific natural disasters on household expenditure. The results show that households in big earthquake regions, who were directly affected by a big earthquake, were badly affected. This is shown from the coefficient of all expenditure categories which are negatively correlated with A in big earthquake areas. There was no serious effect from small earthquake disasters, in fact, those households who were not affected directly by small earthquakes in small earthquake regions had a positive and significant impact of disasters on total household expenditure, and for those households who were affected directly by disasters, they also had a positive impact of disasters on total expenditure and market purchased expenditure. Disasters were only negatively correlated with own produced expenditure for those households who were directly affected by small earthquakes. That is very true since all the farms owned by households which were directly affected were destroyed during a small earthquake. Moreover, for households in flood prone regions, there were positive and significant impacts of floods on own produced expenditure for those households who live in flood prone regions but were not directly affected. This observation could well be true since, for those who were directly affected by floods, there was destruction of their farms and farmland in the flooded regions, which led to a reduction in production and caused an increase in food prices. So for those who were not directly affected by flooding, they could get their food from their own farm products instead of buying from the markets. In addition to the own produced expenditure, for households in flooded regions, floods caused a lower total and market purchased expenditure.

\section{The Impact of Disasters on Educational Expenditure and Wages}

The results of the impact of disasters on educational expenditure and wages are quite different from food and total expenditure. Especially for educational expenditure, disasters reduce educational expenditure for those who are directly affected by the disasters. As pre-

Table 6: Results the impact of specific disasters on household expenditure

\begin{tabular}{|c|c|c|c|c|c|c|}
\hline & \multicolumn{2}{|c|}{ Total HH exp } & \multicolumn{2}{|c|}{ Buy only } & \multicolumn{2}{|c|}{ Own produced } \\
\hline & 1 & 2 & 3 & 4 & 5 & 6 \\
\hline \multirow[t]{2}{*}{ D Big earthquake } & $0.0903 * *$ & $0.0587^{*}$ & $0.134 * * *$ & $0.114^{* * *}$ & 0.0353 & 0.0326 \\
\hline & $(0.0332)$ & $(0.0326)$ & $(0.0375)$ & $(0.0329)$ & $(0.0577)$ & $(0.0547)$ \\
\hline \multirow[t]{2}{*}{ A Big earthquake } & $-0.111^{* * *}$ & $-0.190 * * *$ & $-0.0422 * * *$ & $-0.133^{* * *}$ & $-0.206^{* * *}$ & $-0.205 * * *$ \\
\hline & $(0.000)$ & $(0.00235)$ & $(0.000)$ & $(0.00234)$ & $(0.000)$ & $(0.00650)$ \\
\hline \multirow[t]{2}{*}{ D Small earthquake } & $0.0844 * *$ & $0.123^{* * *}$ & 0.0138 & 0.0508 & $0.281 * * *$ & $0.325 * * *$ \\
\hline & $(0.0332)$ & $(0.0313)$ & $(0.0375)$ & $(0.0320)$ & $(0.0577)$ & $(0.0531)$ \\
\hline \multirow[t]{2}{*}{ A Small earthquake } & $0.145^{* * *}$ & $0.0412 * * *$ & $0.282 * * *$ & $0.196^{* * *}$ & $-0.0470 * * *$ & $-0.0360 * * *$ \\
\hline & $(0.000)$ & $(0.00560)$ & $(0.000)$ & $(0.00675)$ & $(0.000)$ & $(0.00973)$ \\
\hline \multirow[t]{2}{*}{ D Floods } & $-0.0996^{* *}$ & -0.0419 & $-0.0939 * *$ & -0.0357 & $0.206^{* * *}$ & $0.197 * * *$ \\
\hline & $(0.0332)$ & $(0.0328)$ & $(0.0375)$ & $(0.0327)$ & $(0.0577)$ & $(0.0558)$ \\
\hline \multirow[t]{2}{*}{ A Floods } & $0.0121 * * *$ & $-0.0187 * * *$ & $0.105^{* * *}$ & $0.0658^{* * *}$ & $0.0314^{* * *}$ & $0.0154^{*}$ \\
\hline & $(0.000)$ & $(0.00257)$ & $(0.000)$ & $(0.00296)$ & $(0.000)$ & $(0.00740)$ \\
\hline Additional controls & No & Yes & No & Yes & No & Yes \\
\hline Region dummies & Yes & Yes & Yes & Yes & Yes & Yes \\
\hline Time dummies & Yes & Yes & Yes & Yes & Yes & Yes \\
\hline Observation & 20,791 & 20,791 & 20,791 & 20,791 & 15,797 & 15,797 \\
\hline
\end{tabular}

Note: Robust standard errors in parentheses and asterisks denote statistical significance: *** $1 \%, * * 5 \%, * 10 \%$ Additional controls: urban, household size, parental educations, number of household members. 
sented in Table 7, the impact of disasters on educational expenditure shows that the results in column 1 and 2 for the D and A variables were negatively associated with educational expenditure, but only the A variables are significant. It indicates that all the households that live in disaster regions and are not directly affected by disasters have no serious impact on educational expenditure. On the other hand, for households who are directly affected, they are more likely to reduce their educational expenditure to help in smoothing their consumption of food, since Table 5 shows that food expenditure, especially market purchased expenditure, is not affected by disasters.
Furthermore, columns 3 and 4 show the impact of specific disasters on educational expenditure. The results show that only the households in large earthquake and flood regions, which were directly affected by either the large earthquakes or the floods, have lower educational expenditure. This phenomena could be true because only terrible disasters are negatively associated with educational expenditure. In fact, for households who live in flood prone regions, their educational expenditure is also affected by floods. It might be because all their goods were destroyed in the floods, so in order to smooth their consumption, they cut educational expenditure.

Table 7: Results of the Impact of Natural Disaster on Educational Expenditure

\begin{tabular}{|c|c|c|c|c|}
\hline & \multicolumn{4}{|c|}{ Log educational expenditures } \\
\hline & 1 & 2 & 3 & 4 \\
\hline \multirow[t]{2}{*}{$\mathrm{D}$} & -0.0782 & -0.0407 & & \\
\hline & $(0.0598)$ & $(0.0547)$ & & \\
\hline \multirow[t]{2}{*}{ A } & $-0.162^{*}$ & $-0.281 * * *$ & & \\
\hline & $(0.0872)$ & $(0.0797)$ & & \\
\hline \multirow[t]{2}{*}{ D Big earthquake } & & & 0.0441 & -0.0853 \\
\hline & & & $(0.119)$ & $(0.108)$ \\
\hline \multirow[t]{2}{*}{ A Big earthquake } & & & $-0.251^{*}$ & $-0.279 * *$ \\
\hline & & & $(0.133)$ & $(0.121)$ \\
\hline \multirow[t]{2}{*}{ D Small earthquake } & & & 0.0366 & 0.138 \\
\hline & & & $(0.0996)$ & $(0.0910)$ \\
\hline \multirow[t]{2}{*}{ A Small earthquake } & & & 0.236 & 0.0204 \\
\hline & & & $(0.189)$ & $(0.173)$ \\
\hline \multirow[t]{2}{*}{ D Floods } & & & $-0.213 * *$ & $-0.138^{*}$ \\
\hline & & & $(0.0850)$ & $(0.0777)$ \\
\hline \multirow[t]{2}{*}{ A Floods } & & & $-0.464 * * *$ & $-0.481 * * *$ \\
\hline & & & $(0.175)$ & $(0.160)$ \\
\hline Additional controls & No & Yes & No & Yes \\
\hline Region dummies & Yes & Yes & Yes & Yes \\
\hline Time dummies & Yes & Yes & Yes & Yes \\
\hline Observation & 12,383 & 12,383 & 12,383 & 12,383 \\
\hline
\end{tabular}

Note: Robust standard errors in parentheses and asterisks denote statistical significance: $* * * 1 \%, * * 5 \%,{ }^{*} 10 \%$

Additional controls: urban, household size, parental educations, number of household members. 
Table 8 shows the impact of disasters on wages. Columns 1 and 2 are the results of the impact of disasters on wages in general. It seems that disasters are only negatively associated with households who are directly affected by disasters. The possible explanation for this condition is that households who are directly affected by disasters lose their property or the head of the household may lose his job, causing a decrease in wages. On the other hand, there is a positive and significant impact of disasters on wages, but only for those households in disaster regions which are not directly affected by the disasters. This indicates that for the survivors, there is a shock in the labour market or labour supply because there is a lot of work to be done after a disaster, such as cleaning up and rebuilding, so the wages should rise. In the case of specific natural disasters, all the variables are not significant. Only D in big earthquakes, without controlling for other variables, is positively associated with wages, although this is only significant at the 10 percent level. This phenomena could be true because only households who were affected directly by a big earthquake were supposed to have a negative impact on wages, and for those who were not directly affected by a big earthquake, there was a lot of work to be done after the disaster occurred, so it leads to an increase in wages.

\section{CONCLUSION}

This paper finds that there are no significant effects of disasters on total household expendi-

Table 8: The impact of disasters on wages

\begin{tabular}{|c|c|c|c|c|}
\hline & \multicolumn{4}{|c|}{ Log wages } \\
\hline & 1 & 2 & 3 & 4 \\
\hline \multirow[t]{2}{*}{ D } & $0.103 * *$ & $0.105^{* *}$ & & \\
\hline & $(0.0489)$ & $(0.0461)$ & & \\
\hline \multirow[t]{2}{*}{ A } & 0.0546 & -0.0290 & & \\
\hline & $(0.0694)$ & $(0.0654)$ & & \\
\hline \multirow[t]{2}{*}{ D Big earthquake } & & & $0.155^{*}$ & 0.139 \\
\hline & & & $(0.0917)$ & $(0.0864)$ \\
\hline \multirow[t]{2}{*}{ A Big earthquake } & & & 0.0185 & -0.0790 \\
\hline & & & $(0.102)$ & $(0.0959)$ \\
\hline \multirow[t]{2}{*}{ D Small earthquake } & & & 0.130 & 0.0827 \\
\hline & & & $(0.0884)$ & $(0.0832)$ \\
\hline \multirow[t]{2}{*}{ A Small earthquake } & & & -0.0190 & -0.0947 \\
\hline & & & $(0.162)$ & $(0.153)$ \\
\hline \multirow[t]{2}{*}{ D Floods } & & & 0.0598 & 0.102 \\
\hline & & & $(0.0682)$ & $(0.0644)$ \\
\hline \multirow[t]{2}{*}{ A Floods } & & & 0.125 & 0.0990 \\
\hline & & & $(0.137)$ & $(0.129)$ \\
\hline Additional controls & No & Yes & No & Yes \\
\hline Region dummies & Yes & Yes & Yes & Yes \\
\hline Time dummies & Yes & Yes & Yes & Yes \\
\hline Observation & 17,481 & 17,371 & 17,481 & 17,371 \\
\hline
\end{tabular}

Note: Robust standard errors in parentheses and asterisks denote statistical significance: $* * * 1 \%, * * 5 \%, * 10 \%$

Additional controls: urban, household size, parental educations, number of household members. 
ture for households living in disasters regions, whether they are directly affected or not by the disaster. This finding is similar to Jacobsen's study (2012), on the impact of Hurricane Mith (in 1998) on household incomes in Nicaragua. Jacobsen found that households were not seriously affected by the hurricane in their ability to generate income based on their productive assets. In the case of food expenditure, for the households who were directly affected by the hurricane there were negative and significant impacts of the hurricane on own produced expenditure, but a positive impact on market purchased expenditure.

For educational expenditure, only households who are affected directly by disasters have a lower educational expenditure. This finding is supported by Kochar (1999) who found that households were not able to smooth consumption during a time of crop losses, so they were most likely to reduce educational expenditure, especially for girls. Furthermore, there was no significant impact by disasters on wages. In addition, the results showed that only terrifying and destructive natural disasters were associated with lower household expenditure. So the different types of disasters have different effects on household expenditure. Overall, there is no impact by disasters on total household expenditure. These phenomena show that perhaps households are able to anticipate disasters, or governments and aid agencies are good at distributing disaster relief.

In addition, the limitation of this study is that it could not cover Aceh, as the most destructive region, since the IFLS data that was used in this study excludes Aceh from the sample.

\section{REFERENCES}

Angrist, J. D., \& Krueger, A. 2000.”Empirical Strategies in Labor Economics," in Handbook of Labor Economics, ed. By O. Ashenfelter and D. Card.. Amsterdam: Elsevier, 1277-1366.

Asgary, A., \& Willis, K. G. 1997. Household behaviour in response to earthquake risk: an assessment of alternative theories. Disaster, 21(4), 354-365.

Badan Nasional Penanggulangan Bencana., 2009. Available at http://www.bnpb.go.id/

Cameron, L. A., \& Worswick, C. 2001. Education Expenditure Responses to Crop Loss in Indonesia. Economic Development and Cultural Change, 49(2), 351363.

BIBLIOGRAPHY $\backslash 1 \quad 2057$ Jacobsen, K. T. 2012. In the Eye of the Storm-The Welfare Impacts of a Hurricane. World Development, 40 (12): 2578-2589.

Indonesia Family Life Survey by RAND Corporation., 2009. Available at HYPERLINK "http://www.rand.org/labor/FLS/IFLS.html" http://www.rand.org/labor/FLS/IFLS.html

Kochar, A. 1999. Smoothing consumption by smoothing income: hours-of-work responses to idiosyncratic agricurtural shocks in rural India. The Review of Economics and Statistics, 81(1), 50-61.

Lee, M. J., \& Kang, C. 2006. Identification for difference in differences with cross-section and panel data. Economic Letters, 92, 270276.

Neumayer, E., \& Plumper, T. 2007. The gendered nature of natural disasters: the impact of catastrophic events on the gender gap in life expectancy, 1981-2002. Annals of the Association of American Geographers, 97(3), 551-566.

Ninno, C. D., \& Lundberg, M. 2005. Treading water, the long term impact of the 1998 flood on nutrition in Bangladesh. Economics and Human Biology, 3, 67-96.

Skoufias, E. 2003. Economic crises and natural disasters: coping strategies and policy implications. World Development, 31(7), 1087-1102.

Smith, S. K., \& McCarty, C. 1996. Demographic effects of natural disasters: a case study of Hurricane Andrew. Demography, 33(2), 265-275.

Thomas, T. Christiaensen, L., Do, Q. T., \& Trung, L. D. 2010. Natural disasters and household welfare evidence from Vietnam. The World Bank Development Research Group Poverty and Inequality Team, 1-55.

Ureta, M. 2005. Hurricane Mitch, Family Budget and Schooling in Nicaragua. 
Working Paper, Departement of Economics

Texas A\&M University. 